\title{
The Medial Olivocochlear System Attenuates the Developmental Impact of Early Noise Exposure
}

\author{
Amanda M. Lauer ${ }^{1}$ and Bradford J. MaY ${ }^{1}$ \\ ${ }^{1}$ Department of Otolaryngology-Head and Neck Surgery, Johns Hopkins University, Baltimore, MD 21205, USA
}

Received: 16 June 2010; Accepted: 7 February 2011; Online publication: 23 February 2011

\begin{abstract}
The early onset of peripheral deafness profoundly alters the functional maturation of the central auditory system. A prolonged exposure to an artificial acoustic environment has a similar disruptive influence. These observations establish the importance of normal patterns of sound-driven activity during the initial stages of auditory development. The present study was designed to address the role of cochlear gain control during these activity-dependent developmental processes. It was hypothesized that the regulation of auditory nerve activity by the medial olivocochlear system (MOCS) would preserve normal development when the immature auditory system was challenged by continuous background noise. To test this hypothesis, knock-out mice lacking MOCS feedback were reared in noisy or quiet environments and then evaluated with behavioral paradigms for auditory processing deficits. Relative to wild-type controls, noise-reared knock-out mice showed a decreased ability to process rapid acoustic events. Additional anatomical and physiological assessments linked these perceptual deficits to synaptic defects in the auditory brainstem that shared important features with human auditory neuropathy. Our findings offer a new perspective on the potentially damaging effects of environmental noise and how these risks are ameliorated by the protective role of MOCS feedback.
\end{abstract}

Keywords: activity-dependent development, olivocochlear feedback, environmental noise, nicotinic acetylcholine receptor, temporal processing deficit, auditory neuropathy

\section{INTRODUCTION}

It is well established that the maturation of the central auditory system is shaped by sound-driven activity (for a review, see Sanes and Walsh 1998). These developmental processes can be disrupted by prolonged sound exposures that alter normal patterns of auditory activity (Sanes and Bao 2009). As a result, an individual who is exposed to environmental noise at a young age may manifest severe processing deficits as an adult (Tallal et al. 1998).

Animal studies suggest that the nature of an environmentally induced processing deficit is dictated by the physical properties of the sound exposure. For example, an early exposure to continuous white noise delays the emergence of adult tonotopic organization and frequency selectivity in auditory cortex (Chang and Merzenich 2003). An exposure to temporally modulated noise degrades stimulus entrainment (Zhou and Merzenich 2008; 2009). An exposure to repeating transients disrupts stimulus following responses and frequency selectivity in the inferior colliculus (Sanes and Constantine-Paton 1985a, b).

A chronic reduction in sound-evoked activity exerts equally pervasive effects on auditory development. A history of mild conductive loss can impede the refinement of higher-order cognitive processes, such as, speech recognition, auditory memory, and sound segregation (Gravel and Ruben 1996). Disordered patterns of speech and language development can be
Correspondence to: Amanda M. Lauer - Department of Otolaryngology-Head and Neck Surgery · Johns Hopkins University · Baltimore, MD 21205, USA. email: alauer2@jhmi.edu 
reversed by the timely initiation of aided auditory function in deaf children (Sininger et al. 1999; Shepherd et al. 2006). The underlying mechanisms for successful interventions remain poorly understood and are just beginning to be addressed by laboratory studies (Ryugo et al. 2005; Moore and Shannon 2009).

Given the wealth of knowledge on the importance of sound-driven activity during the development of the central auditory system, surprisingly little is known about how these processes are influenced by the efferent pathways that regulate the response of the auditory periphery to environmental noise. In particular, the medial olivocochlear system (MOCS; Wiederhold 1970; Warr and Guinan 1979) can adjust the gain of cochlear sensitivity by modulating the active electromotile properties of outer hair cells (OHCs). The resulting decrease in cochlear amplification protects the ear from the damaging effects of very loud sounds (Wiederhold 1970; Liberman 1991) and improves listening in background noise (Dewson and Efferent 1968; May and McQuone 1995). MOCS activation also stabilizes sound-evoked cochlear potentials (Maison et al. 1997) and may be almost constantly active in temporally varying environments (Maison et al. 2001).

The present study proposes another benefit for the MOCS regulation of sound-driven activity. By reducing the response of the auditory nerve to environmental noise, MOCS efferent feedback may protect the central auditory system during critical stages of activity-dependent development. To test this prediction, the effects of early noise exposures were characterized in knock-out mice that lack MOCS feedback (Vetter et al. 1999). Our findings suggest that MOCS feedback increased a developing animal's resistance to the disruptive effects of environmental noise. When this system was compromised, the resulting deficits were manifested as an impairment of brainstem processing that shared many of the anatomical and physiological features of human auditory neuropathy.

\section{METHODS}

\section{Subjects}

All subjects were obtained from breeding facilities that are maintained within the laboratory. Knock-out mice with a homozygous null mutation of the $\alpha 9$ nicotinic acetylcholine receptor subunit $(\alpha 9 \mathrm{KO})$ were originally generated by Vetter et al. (1999). Our $\alpha 9 \mathrm{KO}$ breeders were obtained from Jackson Labs

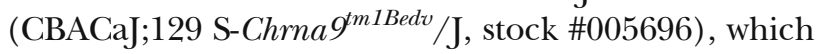
used a mixed CBA/CaJ and 129 S6/SvEvTac background to avoid generalized hearing abnormalities in the original strain. Deletion of the $\alpha 9$ subunit eliminates MOCS-mediated suppression of soundevoked cochlear potentials (Vetter et al. 1999), indicating functional "de-efferentation" of OHCs. Homozygous wild-type (WT) mice from the same background strain were used to evaluate the effects of sound exposures on subjects with a functional MOCS. A total of $34 \alpha 9 \mathrm{KO}$ mice and $31 \mathrm{WT}$ mice were tested. Both male and female mice were used.

Mice were housed in the restricted-access (quiet) or heavy-traffic (noisy) vivaria from birth but were periodically removed from these rooms for behavioral and physiological evaluation. Testing paradigms were optimized for maximum efficiency and were typically completed in less than $1 \mathrm{~h}$. Behavioral measures of temporal acuity were conducted at 4-5 weeks of age. Auditory brainstem response (ABR)-based measures of hearing thresholds were performed at $6-7$ weeks of age. ABR-based measures of temporal acuity were performed at approximately 2 months of age. All procedures were approved by the Animal Care and Use Committee of Johns Hopkins University.

\section{Environmental noise conditions}

Noise levels in the restricted-access and heavy-traffic vivaria have been described elsewhere (Lauer et al. 2009). The heavy-traffic vivarium represented noise levels that are typically experienced by laboratory mice in high-density institutional housing facilities (Fig. 1A). This room was shared by approximately 50 investigators and consequently had frequent personnel traffic and equipment use during the work day. Sound-level measurements inside cages indicated static noise levels that exceeded $40 \mathrm{~dB}$ sound pressure level (SPL) in third octave bands spanning the most sensitive range of mouse hearing. Most of this background noise was generated by an individual cage ventilation system. Investigator activity introduced transient noise that exceeded background noise levels by $20-30 \mathrm{~dB}$.

The restricted-access vivarium was a closer approximation of the natural rearing habitat of the mouse (Fig. 1B). This room had infrequent personnel traffic and static filter top cages, and was ventilated with conventional ceiling-mounted ducts. Ambient noise levels remained below $40 \mathrm{~dB}$ SPL with few investigator-generated transients. The spectra of the two variants of cage noise showed their largest differences at frequencies below $10 \mathrm{kHz}$ (Fig. 1C). The rooms were similar in non-acoustic environmental factors such as size, light cycle, humidity, and temperature.

\section{Behavioral measures of temporal acuity}

Behavioral measures of temporal acuity were based on a variant of pre-pulse inhibition (PPI; Hoffman and 

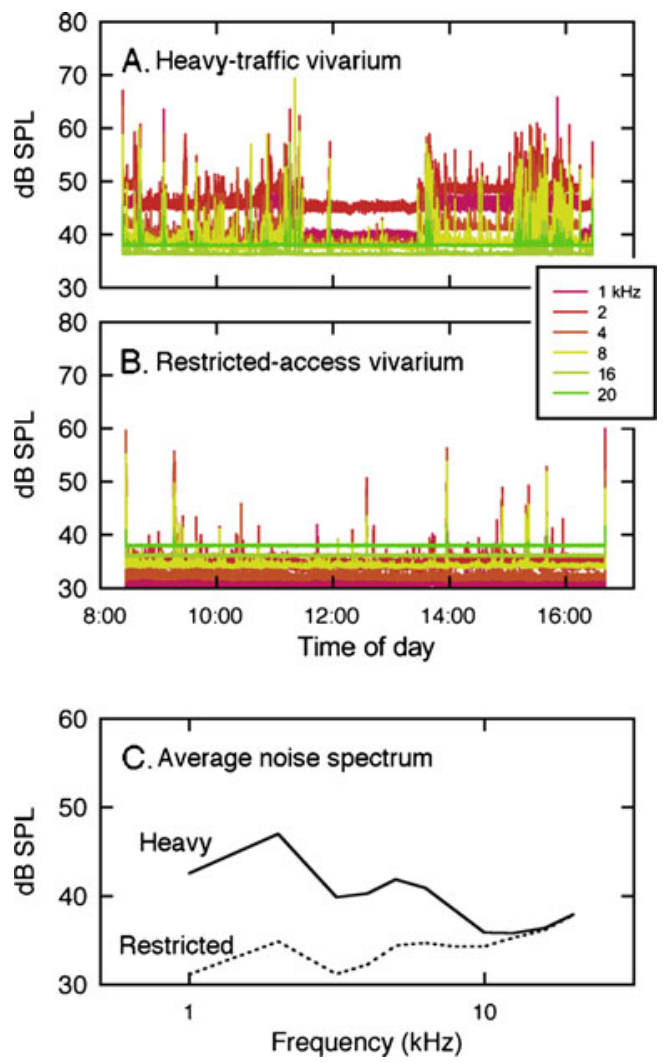

FIG. 1. One third octave band sound levels measured over an 8-h period in a noisy heavy-traffic vivarium (A) and quiet restrictedaccess vivarium (B). Acoustic transients were more frequent in the noisy room. Differences in the average noise spectra of the two rooms were concentrated at frequencies below $10 \mathrm{kHz}(\mathbf{C})$.

Fleshler 1963). With conventional PPI procedures, acoustic startle reflexes (ASRs) are elicited by sudden bursts of high-level broadband noise. On some trials, the startle-eliciting stimulus is preceded by a low-level sound, which is designated the pre-pulse. PPI is indicated when the ASR shows a decrease in magnitude on trials with the pre-pulse relative to trials without the pre-pulse.

Studies in laboratory mice suggest that inhibition of the ASR may be enhanced by substituting the prepulse with a silent gap in an otherwise continuous background of broadband noise (Ison et al. 1998; Ison and Allen 2003). This procedure is known as gapinhibition of the acoustic startle reflex (GIASR). In our version of the GIASR task, the startle-eliciting stimulus was a 20-ms burst of broadband noise at 115 dBA. The interrupted noise background was presented at $70 \mathrm{dBA}$. Stimulus configurations for the GIASR task are depicted in Figure 2A.

Because GIASR depends upon the ability of the auditory system to process two auditory events in rapid succession, the functional limits of temporal acuity are reflected in stimulus conditions that elicit significant inhibitory effects. Our behavioral measures exploited this relationship to explore the consequences of early sound exposure on the development of temporal processing. It was hypothesized that noise-reared mice would show deficits of temporal acuity by requiring longer lead times in the GIASR task.

Each GIASR test session consisted of a minimum of ten trial blocks, with each block containing two reference trials in which the noise remained on and seven gap trials in which the noise was turned off with lead times of $1,2,4,6,8,10$, or $15 \mathrm{~ms}$. The order of presentation was randomized for the nine trials in each block. The timed interval between trials was varied at random between 5 and $15 \mathrm{~s}$. After the intertrial interval expired, the subject's movements were

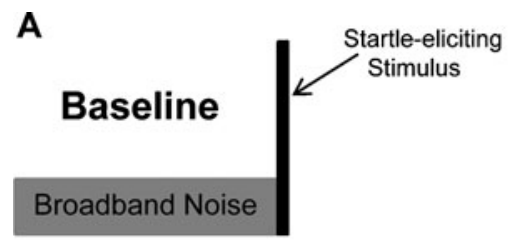

B

Conventional ABR

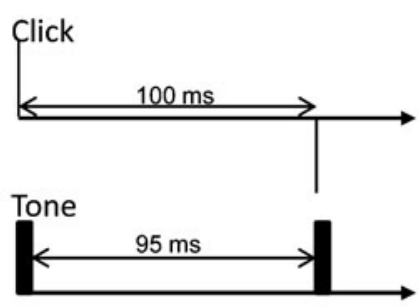

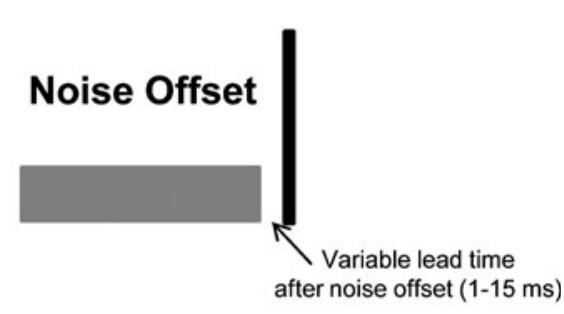

C

Modified ABR
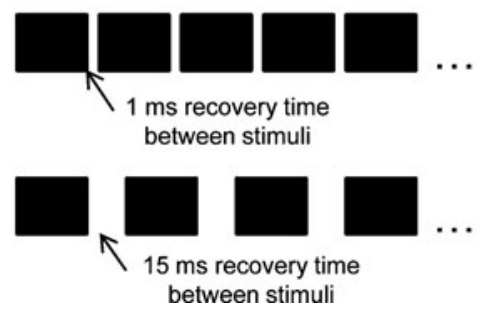

FIG. 2. Stimulus paradigms for the three experiments. A The GIASR task measured the subject's ability to process rapid acoustic events. On baseline trials, a startle-eliciting stimulus was presented with continuous background noise. On gap trials, the background noise was turned off with varying lead times before the presentation of the startle-eliciting stimulus. B Conventional ABR paradigm for measuring the integrity of sound processing in the auditory nerve and brainstem. Clicks or 5-ms tone bursts were presented at a rate of 10 stimuli/s to allow 95-100 ms of recovery between stimuli. C Modified ABR paradigm for measuring the effects of presentation rate on the magnitude and latency of evoked potentials. Tones were presented with longer durations (20 ms) and shorter recovery periods (1-15 ms). 
monitored with a piezoelectric sensor on the holding cage. When the mouse remained still for a period of $5 \mathrm{~s}$, a trial was presented.

During the trial period, the background noise was turned off with the appropriate lead time, or left on in the case of a baseline trial, and the startle-eliciting stimulus was presented. Coincident with the onset of the startle stimulus, the peak-to-peak amplitude of the mouse's ASR was measured over a 100-ms interval. At the conclusion of the test session, relative measures of gap-inhibition were computed at each lead time from the ratio of the average ASR amplitude on gap versus reference trials.

\section{Electrophysiological measures of brainstem processing}

Previous studies of the effects of early noise exposures on mice describe a neuropathic condition in which hearing thresholds remain normal, but temporal synchrony is degraded (Kujawa and Liberman 2009). To investigate similar effects in noise-reared $\alpha 9 \mathrm{KO}$ mice, ABRs were recorded from the four treatment groups. The evoked responses were expected to confirm normal hearing sensitivity by showing equivalent waveform magnitudes at threshold sound levels. The quality of synchronization was inferred from the magnitude and latency of responses at suprathreshold sound levels. Quietreared WT mice served as normal controls for all response measures.

Mice were anesthetized during ABR recordings with intraperitoneal injections of $125 \mathrm{mg} / \mathrm{kg}$ ketamine and $12.5 \mathrm{mg} / \mathrm{kg}$ xylazine in $14.25 \%$ ethyl alcohol. Core body temperature was maintained with a regulated heating pad at $37 \pm 1^{\circ} \mathrm{C}$. Differential recordings were made with subdermal platinum needle electrodes placed behind the left pinna (inverting), at the dorsal midline of the skull (non-inverting), and in the left hind leg (ground). Averaged ABR waveforms were obtained by presenting clicks or pure tones (5-ms duration, $0.5 \mathrm{~ms}$ rise/fall times) at a rate of $10 \mathrm{stimuli} / \mathrm{s}$ (Fig. 2B). Responses were amplified, filtered from $300-3,000 \mathrm{~Hz}$, digitized, and averaged over 300 repetitions. The ABR signal magnitude was calculated from the averaged peak-to-peak voltage in a 5-ms time window beginning $1 \mathrm{~ms}$ after stimulus onset. The electrical noise level was calculated from the peak-to-peak voltage in a 5-ms window beginning $20 \mathrm{~ms}$ after stimulus offset. Threshold was calculated as the stimulus level that produced a peak-to-peak response that was two standard deviations above electrical noise. This value was interpolated from the input-output function relating ABR magnitude to stimulus level.
Electrophysiological measures of temporal acuity

Conventional ABR procedures are designed to optimize response magnitude by reducing stimulus refractory effects. Short-duration stimuli (an instantaneous click or 5-ms tone) are presented at a slow rate (10 stimuli/s) to allow recovery between stimuli. To investigate the importance of the recovery period in a manner that more closely approximated the temporal challenge of the GIASR paradigm, our ABR-based measures of temporal acuity increased the duration of tonal stimuli to $20 \mathrm{~ms}$ and shortened the inter-stimulus interval between successive stimuli (Fig. 2C). A similar manipulation of ABR presentation rate has been used to explore temporal processing deficits in human listeners (Krizman et al. 2010).

The high-temporal-demand ABRs were recorded in response to tone bursts that were fixed in frequency $(8 \mathrm{kHz})$, duration (20 ms, 0.5 -ms rise/fall times), and level ( $80 \mathrm{~dB}$ SPL) but varied in inter-stimulus interval (ISI). The silent period between successive tone bursts was matched to the lead time conditions of the GIASR experiments (1, 2, 4, 6, 8, 10, or $15 \mathrm{~ms})$.

The effects of ISI on the ABR waveform were characterized in terms of the amplitudes of wave 1 (peak-to-peak voltage difference between $\mathrm{P} 1$ and N1) and wave 2 (difference between P2 and N2), and the interpeak latency difference between P1 and $\mathrm{P} 2$.

\section{RESULTS}

The hypothesized developmental risk of early sound exposure was evaluated by comparing hearing sensitivity and temporal acuity in groups of mice that were reared in either the heavy-traffic vivarium (noise) or the restricted-access vivarium (quiet). The ability of the MOCS to ameliorate the noise exposure was investigated by comparing the magnitude of environmentally induced deficits in $\alpha 9 \mathrm{KO}$ mice to WT controls.

\section{Effect of rearing environment on GIASR}

Group-wise comparisons of WT mice revealed negligible differences between subjects that were reared in the heavy-traffic or restricted-access vivaria (Fig. 3A). The noise-reared mice showed less inhibition at shorter lead times than the quietreared mice, but the differences were not statistically significant. All subjects displayed the expected monotonic decline in ASR magnitude with increasing lead times.

The most striking feature of functions from quietreared $\alpha 9 \mathrm{KO}$ mice (Fig. 3B) was the potentiated startle 

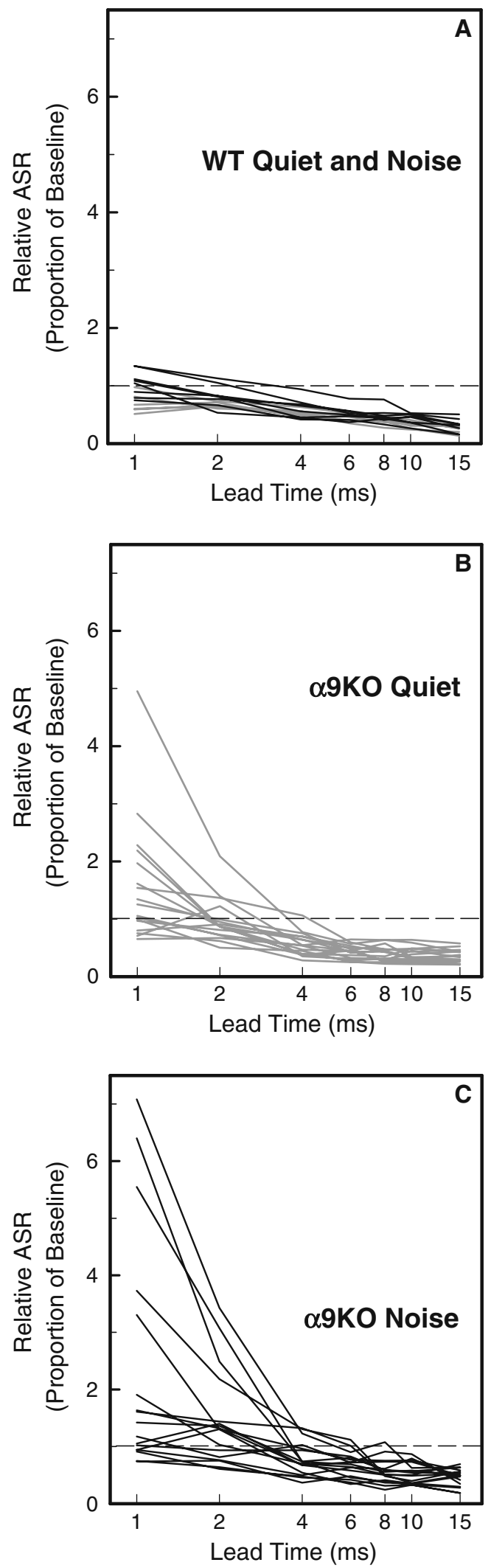

FIG. 3. Individual lead time functions for the GIASR task. A Baseline controls for quiet-reared (gray) and noise-reared WT mice (black). Relative ASR is plotted in relation to the lead time of noise offset. A relative ASR of less than 1.0 (dotted line) indicates GIASR. B, C Lead time functions for quiet-reared and noise-reared $\alpha 9 \mathrm{KO}$ mice. response at a lead time of $1 \mathrm{~ms}$. This exaggeration of the startle response has been previously described in older C57BL/6 J mice (Ison et al. 2007). Because the effect came at a later age relative to the age-related loss of cochlear hair cells, it has been attributed to a reorganization of the central afferent pathways that follows the disruption of peripheral inputs. Inhibitory effects were similar to those of WT mice at longer lead times.

Noise-reared $\alpha 9 \mathrm{KO}$ mice (Fig. 3C) showed more enhancement than quiet-reared WT mice at the shortest lead times. The asymptote of their lead time function also indicated less maximum inhibition at long gap intervals. In comparison to the other treatment groups, noise-reared $\alpha 9 \mathrm{KO}$ mice displayed the greatest inter-subject variability.

The statistical distribution of inhibitory effects among the four treatment groups is summarized by the "box-and-whisker" plots in Figure 4A. The vertical height of each box spans the inter-quartile range or middle $50 \%$ of the group distribution. The box is bisected by the median score. Error bars reach to the lowest and highest score within \pm 1.5 inter-quartile ranges. Data falling outside these limits are plotted as individual outliers. For reference, the dashed line in each panel indicates a relative ASR of 1. Data falling below the line are evidence of GIASR.

Quiet-reared WT mice displayed GIASR at all lead times. Noise-reared WT mice and quiet-reared $\alpha 9 \mathrm{KO}$ mice showed slightly less GIASR, but tended to display generalized inhibitory responses at lead times as short as $2 \mathrm{~ms}$. Strong inhibitory effects did not develop in noise-reared $\alpha 9 \mathrm{KO}$ mice until lead times reached $4 \mathrm{~ms}$.

Regardless of rearing environment, some $\alpha 9 \mathrm{KO}$ mice in both treatment groups produced normal lead time functions, while others exhibited strong facilitation and diminished inhibition. The proportion of mice with abnormal functions and the magnitude of their temporal deficits increased with noise exposure, and the noise effect was compounded in mice with compromised MOCS feedback.

The statistical significance of the treatment effect was evaluated by performing a one-way analysis of variance (ANOVA) on the rank scores of the distributions in Figure 4A (non-parametric Kruskal-Wallis Test, implemented as kruskalwallis function in MATLAB). Post hoc comparisons were conducted to determine which groups differed significantly from quiet-reared WT mice at each lead time. The 95\% confidence intervals (CIs) for the rank scores of each distribution are shown in Figure 4B (ANOVA with Bonferroni adjustments for multiple comparisons, implemented as multcompare function in MATLAB). Results for quietreared WT mice are shaded in each panel. CIs that fall to the right of the shaded region represent a statistically 
A
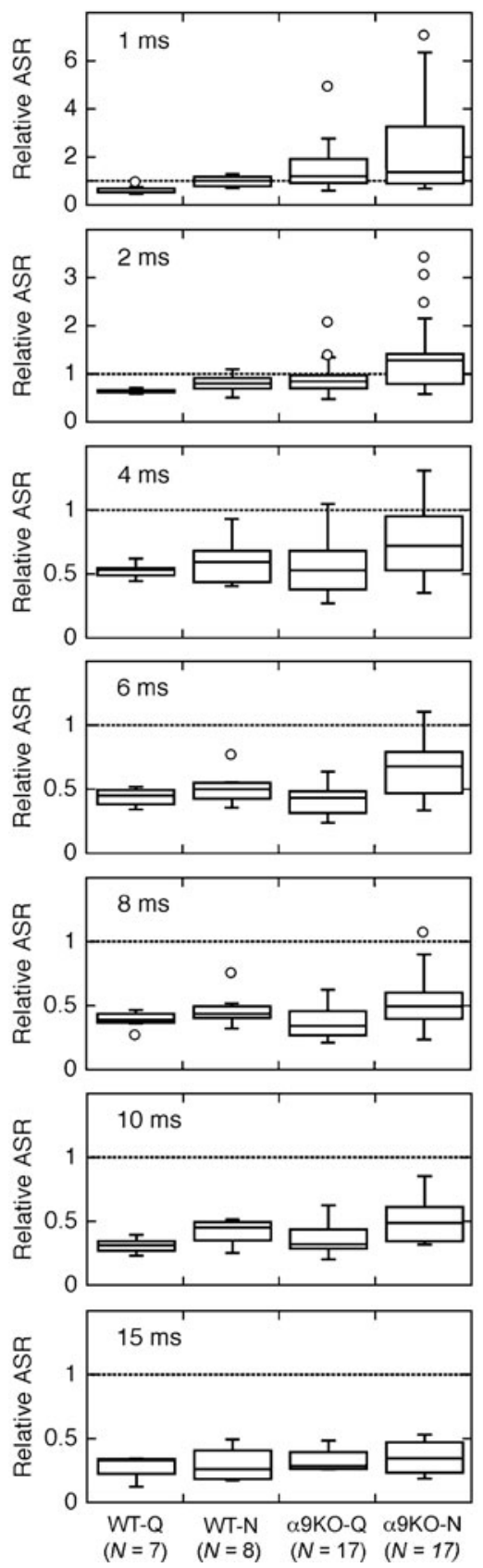

B
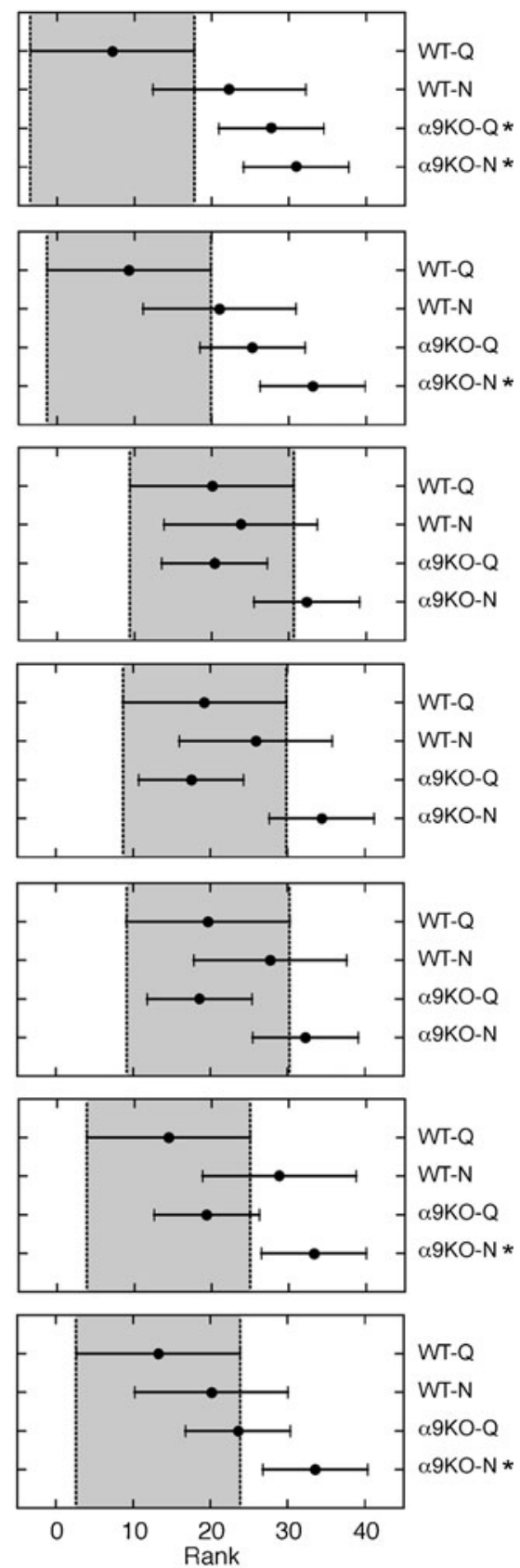

FIG. 4. A statistical analysis of the effects of treatment group on GIASR. A Boxplots of the distribution of ASR measures for each lead time. See text for explanation of plotting conventions. B 95\% confidence intervals (Cls) for the global rank scores of each distribution. Cls that fall entirely outside the baseline responses of quiet-reared WT mice (shaded areas) indicate statistically significant treatment effects $(P<0.05$, asterisks). significant decrease in inhibition relative to the $\mathrm{WT}$ controls $(P<0.05)$.

There were no significant group differences between WT mice that were reared in the heavy-traffic and restricted-access vivaria. A significant difference was noted for quiet-reared $\alpha 9 \mathrm{KO}$ at the shortest lead time ( $1 \mathrm{~ms}$ ). The startle magnitudes of quiet-reared $\alpha 9 \mathrm{KO}$ mice also were consistently less inhibited than those of WT controls at the 2-ms lead time, although the comparison failed to reach statistical significance. Noise-reared $\alpha 9 \mathrm{KO}$ mice displayed significant decreases in GIASR at lead times of 1, 2, 10, and 15 ms. Decreases in inhibition were not statistically significant at lead times of 4,6 , and $8 \mathrm{~ms}$, but the highest rank positions (i.e., least inhibited startle responses) were produced by noise-reared $\alpha 9 \mathrm{KO}$ mice.

The analysis in Figures 3 and 4 highlights a weakness of the group-wise statistical comparisons. Relative to the tight distributions of quiet-reared WT mice, mice in the remaining treatment groups produced lead time functions that ranged from the best performance of normal controls to severely abnormal responses. The number of affected individuals and the most extreme abnormalities were 
associated with noise-reared $\alpha 9 \mathrm{KO}$ mice, but even this treatment produced some mice with normal responses.

\section{Effect of rearing environment on $\mathrm{ABR}$ thresholds}

The effect of rearing environment on hearing sensitivity was evaluated by collecting ABR thresholds with clicks and pure tones at 8, 16, and $32 \mathrm{kHz}$. The distributions of thresholds for each treatment group are presented as "box-and-whiskers" plots in Figure 5A. The median click thresholds of noisereared WT mice and quiet-reared controls differed by $4.2 \mathrm{~dB}$. Quiet-reared and noise-reared $\alpha 9 \mathrm{KO}$ mice showed threshold elevations of 3.0 and $4.3 \mathrm{~dB}$, respectively. Median thresholds for $16-$ and $32-\mathrm{kHz}$ tones fell within $\pm 5 \mathrm{~dB}$ of the baselines that were obtained in quiet-reared WT mice. The largest threshold differences were observed at $8 \mathrm{kHz}$, where quiet-reared WT and $\alpha 9 \mathrm{KO}$ mice showed equivalent sensitivity, but noise-reared WT mice and $\alpha 9 \mathrm{KO}$ mice showed threshold elevations of 7.3 and $10.2 \mathrm{~dB}$, respectively.

The statistical significance of threshold differences between treatment groups was evaluated by performing a one-way ANOVA on the rank scores of the threshold distributions (Kruskal-Wallis test), followed by post hoc comparisons with Bonferroni corrections. The resulting $95 \%$ CIs are shown in Figure 5B. As indicated by the overlapping CIs, none of the group-wise comparisons attained statistical significance. Nevertheless, it is clear that noise-reared $\alpha 9 \mathrm{KO}$ mice tended to occupy the highest ranks of thresholds at both 8 and $16 \mathrm{kHz}$.

The heterogeneity of GIASR and threshold measures among noise-reared $\alpha 9 \mathrm{KO}$ mice raised the possibility that subjects with large threshold shifts may have contributed to the decline in temporal acuity within this treatment group. To illustrate the strength of correlation, relative startle magnitude is plotted in relation to the ABR threshold of each noise-reared $\alpha 9 \mathrm{KO}$ mouse in Figure 6 . The four panels summarize the correlations at lead times of $1,2,10$, and $15 \mathrm{~ms}$, where $\alpha 9 \mathrm{KO}$ mice exhibited statistically significant decreases in GIASR (Fig. 4). At the different lead times, the one measure of relative ASR from each mouse is plotted twice in relation to the subject's thresholds at 8 and $16 \mathrm{kHz}$.

Linear regressions (implemented in MATLAB using the regress function) found statistically significant correlations $(P<0.05)$ between relative ASR and $8-\mathrm{kHz}$ thresholds at lead times of 1 and $2 \mathrm{~ms}$. As previously noted (Ison et al. 2007), these results suggest that the exaggerated ASR at short lead times is a manifestation of a hyperacusis-like phenomenon in mice with hearing loss. Despite the statistical significance of this relationship, affected mice in the present study showed modest threshold shifts $(\sim 10 \mathrm{~dB})$ relative to
A

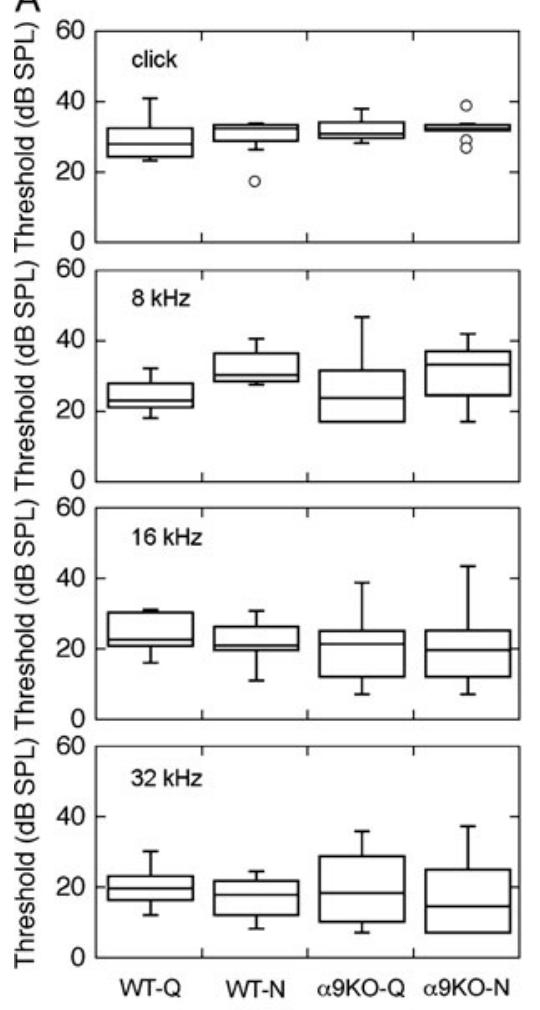

B

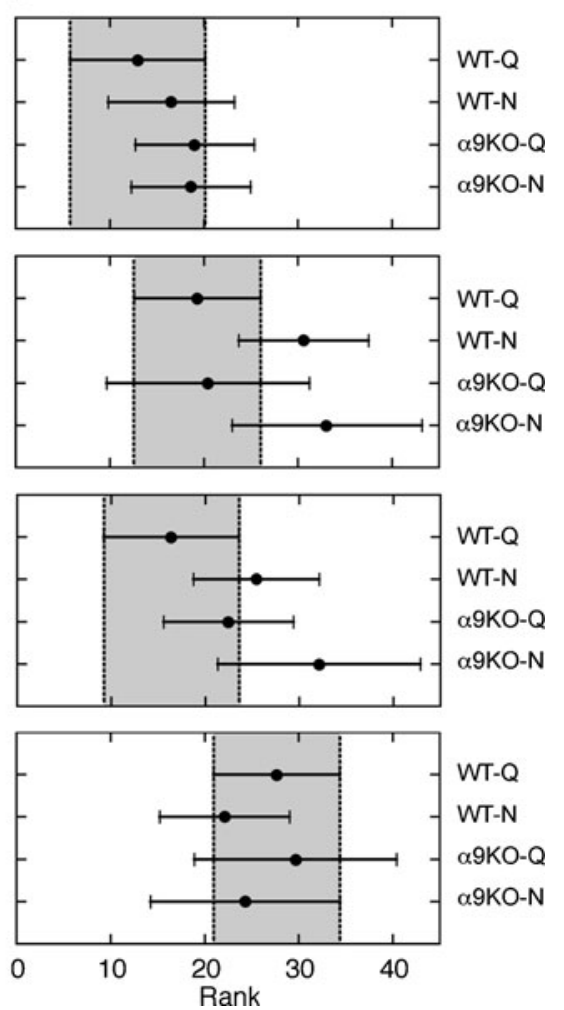

FIG. 5. A statistical analysis of the effects of treatment group on hearing sensitivity. ABR thresholds were obtained with clicks and tones $(8,16$, and $32 \mathrm{kHz})$. Threshold distributions and the 95\% confidence intervals for global rank scores are shown in $\mathbf{A}$ and $\mathbf{B}$, as described in Figure. 4. Thresholds did not vary significantly across treatment groups. 

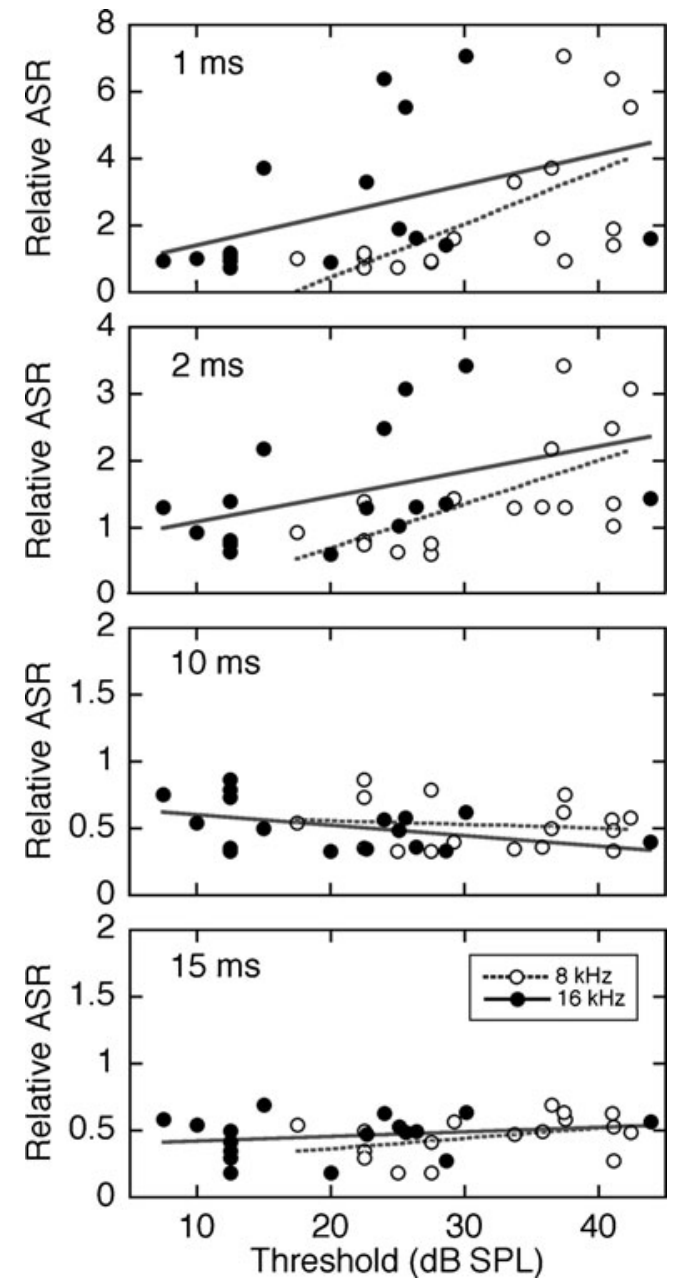

FIG. 6. Correlations between $A B R$ thresholds and relative ASR measures. Results are shown for noise-reared $\alpha 9 \mathrm{KO}$ mice at the four lead times that produced statistically significant decreases in GIASR (Fig. 4B). At each lead time, the ASR is plotted twice in relation to the 8- and $16-\mathrm{kHz}$ thresholds of the same subject. The same thresholds are repeated at all four lead times. Linear fits (dashed and solid lines) revealed statistically significant correlations $(P<0.05)$ between ASR and $8-\mathrm{kHz}$ thresholds at lead times of 1 and $2 \mathrm{~ms}$.

quiet-reared WT mice. The loss of GIASR at longer lead times was not correlated with threshold.

Effects of rearing environment on stimulus recovery

The observation of decreased temporal resolution in the GIASR task implies that noise-reared $\alpha 9 \mathrm{KO}$ mice exhibit a diminished ability to encode a rapid series of stimulus presentations. Because the conventional $A B R$ threshold paradigm was designed to minimize the refractory effects of one stimulus presentation on the next, additional ABR measures were performed to challenge stimulus recovery with longer stimulus durations (20-ms tone bursts) and shorter ISIs (1-15 ms).
Prior to testing with rapid stimulus presentations, baseline ABRs were recorded by presenting $8-\mathrm{kHz}$ tone bursts with a duration of $5 \mathrm{~ms}$ and ISI of $95 \mathrm{~ms}$. The brief stimulus duration and long recovery period were expected to evoke robust responses with minimal adaptation. Under these conditions, the baseline waveforms of all treatment groups displayed a similar pattern of at least four to five prominent peaks (Figs. 7A, B). A statistical analysis of waves 1 and 2 revealed no consistent differences between $\alpha 9 \mathrm{KO}$ mice relative to WT controls. Regardless of olivocochlear status and rearing environment, wave 1 amplitudes ( $\mathrm{P} 1$ to $\mathrm{N} 1$ voltage) were equivalent (Fig. 7C; $P>0.05$, KruskalWallis test with adjusted post hoc comparisons). There also was no statistically significant difference in the interpeak latencies of waves 1 and 2 (Fig. 7D). These results suggest that the peripheral response of $\alpha 9 \mathrm{KO}$ mice rivals normal performance at slow rates of auditory stimulation.

Reducing the recovery period between stimulus presentations had little effect on the ABR waveforms of WT mice (Fig. 8A). At ISIs as short as $1 \mathrm{~ms}$, the mice produced ABRs with four to five distinct waves that resembled their non-adapted baselines (Fig. 7A). Quiet-raised $\alpha 9 \mathrm{KO}$ mice also produced clearly peaked ABR waveforms, although the 1-ms ISI produced later waves (e.g., waves 3 and 4) that were smaller and less distinct than non-adapted baselines (Fig. 8B). ABR waveforms in noise-reared $\alpha 9 \mathrm{KO}$ mice lacked prominent peaks (Fig. $8 \mathrm{~B}$ ). In most instances, later waves were indistinguishable from background noise. The effects were exacerbated by shorter ISIs.

The statistical significance of the effect of ISI on the four treatment groups was evaluated by performing a two-way ANOVA on prominent morphological features of the ABR waveform (non-parametric Friedman test, implemented in MATLAB as the friedman function). The relationship between ISI and the median magnitude of wave 1 is plotted in Figure 8C. Error bars indicate the inter-quartile range of responses from the eight mice in each treatment group. A statistical analysis of these data indicated that wave magnitude was significantly influenced by treatment group $(P<0.01)$, but not ISI. Post host comparisons attributed the difference between groups to a significant decrease in wave 1 for quiet-reared and noise-reared $\alpha 9 \mathrm{KO}$ mice relative to quiet-reared WT mice $(P<0.05)$. The smaller decrease for noisereared WT mice did not attain statistical significance.

The statistical distributions of interpeak latencies (P1 to P2) are compared in Figure 8D. Once again, a two-way ANOVA found a significant effect of treatment group $(P<0.01)$. In this case, post hoc comparisons linked the effect to the isolated increase in the interpeak 

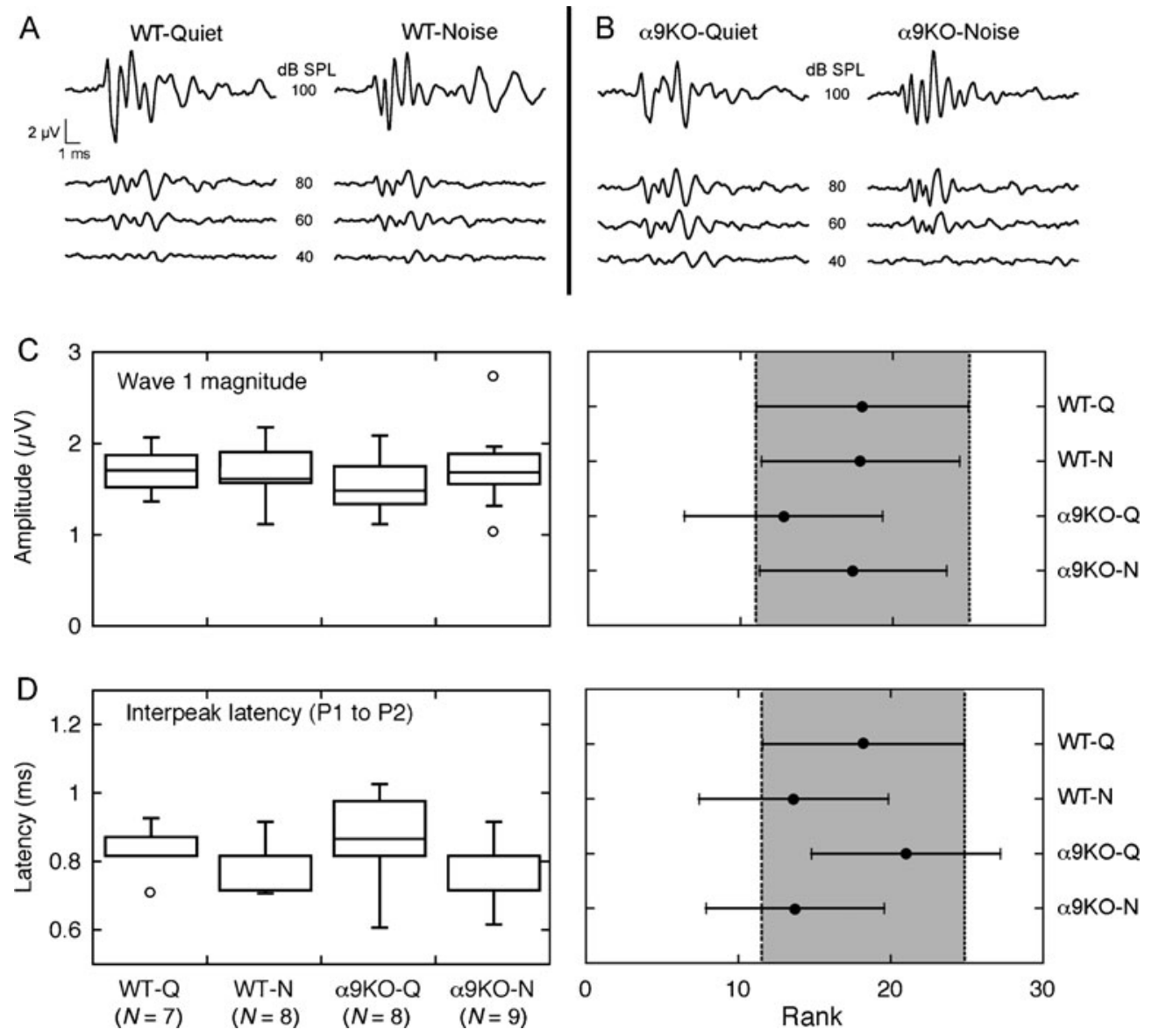

FIG. 7. Comparison of ABRs obtained with conventional procedures. To minimize the effects of one stimulus presentation on the next, 8-kHz tone bursts were presented with a short duration (5 ms) and a long ISI (95 ms). A, B Waveforms from a representative mouse in each of the four treatment groups. Numerical labels indicate

presentation level. C, D Boxplots and 95\% Cls for the magnitude of wave 1 and the interpeak latency separating P1 and P2 for all mice that were tested with $8-\mathrm{kHz}$ tones at $80 \mathrm{~dB}$ SPL. The features did not show statistically significant treatment effects.

latency of noise-reared $\alpha 9 \mathrm{KO}$ mice relative to quietreared WT mice $(P<0.05)$.

The effect of ISI on the magnitude of wave 2 are summarized in Figure 8E. As previously noted for wave 1, a two-way ANOVA indicated a significant effect of treatment group that was associated with a significant decrease in wave 2 magnitude among both groups of $\alpha 9 \mathrm{KO}$ mice.

\section{DISCUSSION}

The major finding of the present study was the potentially detrimental effect of early noise exposure on the temporal acuity of adult mice. The behavioral and physiological correlates of disordered temporal processing were independent of hearing loss and were induced by noise levels that did not produce overt acoustic trauma. A small percentage of noise-reared WT mice developed the abnormal phenotype, but environmental risk factors were significantly increased

in $\alpha 9 \mathrm{KO}$ mice with a compromised MOCS. These results suggest that efferent-mediated adjustments of sound-driven activity may play an important role in the developmental processes that shape sound coding in the central auditory pathways.

\section{The protective role of the MOCS}

Despite detailed physiological characterizations of MOCS influences on the cochlea and auditory nerve, the broader functional implications of this efferent feedback remain controversial. Decades of research can be distilled into three basic observations.

1. The MOCS protects the cochlea during intense sound exposure (Rajan 1988; Liberman 1991). Detractors of this interpretation have suggested that unnaturally loud sound exposures have little relevance as biological determinants (Kirk and Smith 2003).

2. The MOCS enhances the perception of auditory signals in background noise (Dewson 1968; May 
and McQuone 1995). The general importance of this feedback is constrained by the limited dynamic range of the noise-reduction effect (Winslow and Sachs 1987).

3. The MOCS initiates activity in the developing auditory nerve that shapes adult sensitivity and frequency selectivity (Walsh et al. 1998). Lesioned kittens do exhibit auditory nerve fibers with high thresholds and broad tuning when they reach adulthood, but these developmental abnormalities have not been replicated with non-surgical approaches. For example, the $\alpha 9 \mathrm{KO}$ mice in the present study lack MOCS feedback from birth but show normal peripheral function as adults (Vetter et al. 1999).

Our present findings may reconcile these seemingly disparate viewpoints. In the context of our paradigm, which incorporates aspects of each major functional interpretation, the potentially damaging effects of environmental noise extend beyond acoustic trauma to include the disruption of auditory development. While acoustic damage typically involves a brief exposure to an unnaturally loud sound, developmental impairments can be induced by a prolonged exposure to commonly encountered sound levels. Presumably, the reduction of sustained noise-driven activity by the MOCS provides sufficient protection to ameliorate this risk.

The ability of the MOCS to enhance auditory signals in background noise also appears advantageous from the perspective of activity-dependent developmental processes. By reducing random patterns of noise-driven activity, the feedback system preserves the response of the auditory nerve to the dynamic information-bearing elements of acoustic signals. These coherent firing patterns may be crucial for the refinement of the synaptic circuitry of the central auditory pathways.

The strength of MOCS protection presumably is dictated by the physical characteristics of the environmental challenge (Liberman and Brown 1986). The acoustic reflex is most effectively driven by binaural sounds of longer duration. High-frequency neurons achieve their highest discharge rates when stimulated with broadband noise. Individual neurons are tuned in frequency and innervate a matching frequency region of the cochlea. Based on these properties, it is likely that sustained noise levels in the heavy-traffic vivarium would evoke a strong efferent response in WT mice. The resulting hyperpolarization of cochlear OHCs would inhibit responses to the background noise that elicited the efferent feedback, as well as any coincident transients. Consequently, the present experimental manipulations do not distinguish which of these acoustic features constituted the greater environmental risk for MOCS-compromised mice.
Impaired temporal processing was expressed in order of increasing prevalence by noise-reared WT mice, quiet-reared $\alpha 9 \mathrm{KO}$ mice, and noise-reared $\alpha 9 \mathrm{KO}$ mice. In the case of WT mice, within-group variability may be explained by an individualized genetic susceptibility to environmental risk factors. Prior anatomical studies have noted large variations in MOCS fiber counts between individuals of the same species (Warr 1992). Functional measures of the strength of olivocochlear feedback, such as the contralateral suppression of distortion product otoacoustic emissions (DPOAEs), also vary greatly between individuals and are correlated with auditory performance in background noise (Giraud et al. 1997; May et al. 2004; but also see Wagner et al. 2008). These results suggest that some WT mice developed temporal processing deficits when reared in background noise because they had naturally weak MOCS protection. This predisposition was amplified by the targeted genetic disruption of cholinergic signaling in the $\alpha 9 \mathrm{KO}$ treatment groups. Noise susceptibility increased to the extent that a number of knock-out mice developed temporal processing deficits even when reared under quiet conditions. As anticipated, the highest percentage of deficits was observed among noise-reared $\alpha 9 \mathrm{KO}$ mice. A particularly intriguing finding for mice with this combined risk was that some individuals resisted the detrimental effects of the noise exposure. The source of this unexplained protection may be resolved by rearing mice in controlled environments that allow precise parametric manipulations of putative risk factors.

\section{Alterations of synaptic transmission in the auditory nerve and ventral cochlear nucleus}

Our electrophysiological results suggest that impaired performance in the GIASR task may be linked to deficits in synaptic transmission between the auditory nerve and VCN. Relative to responses of WT mice, $\alpha 9 \mathrm{KO}$ mice showed statistically significant decreases in the magnitude of ABR waves 1 and 2. The onset of wave 2 also was significantly delayed in noise-reared $\alpha 9 \mathrm{KO}$ mice. These deficits were most apparent when the rate of stimulus presentations was accelerated to increase adaptation effects.

Because wave 1 of the ABR reflects synchronized activity in the auditory nerve, the observed decrease in wave 1 magnitude suggests dys-synchronization, a condition that is broadly classified as auditory neuropathy. Previous studies have shown that a similar neuropathic condition can be induced by acutely exposing 4-8 week old mice to loud levels of noise (Kujawa and Liberman 2006). Although our induc- 

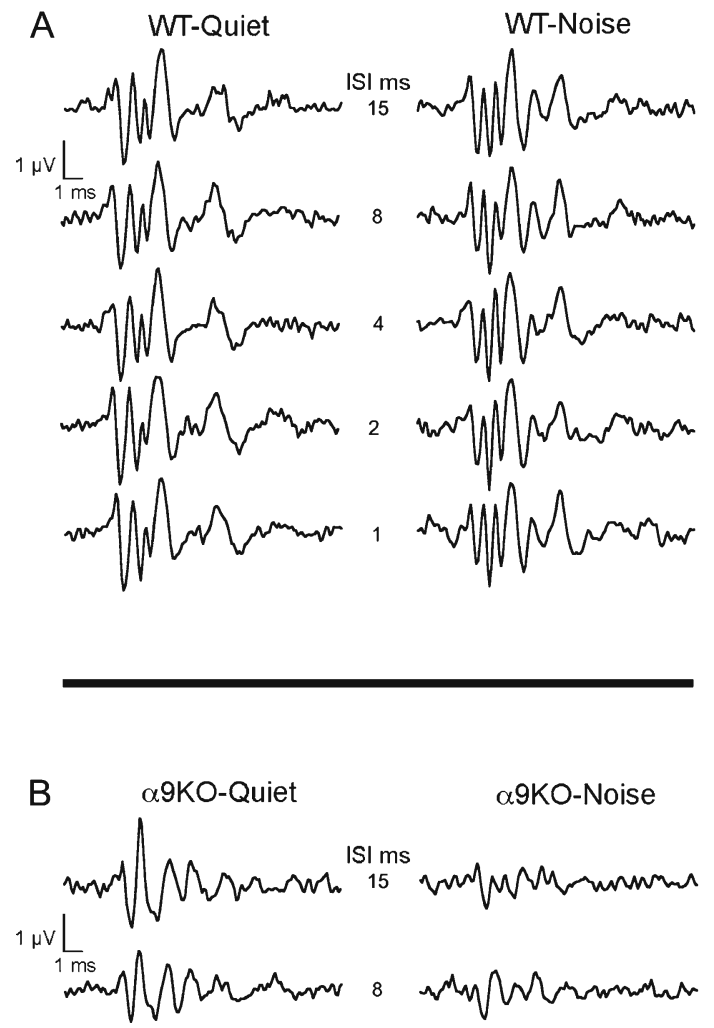

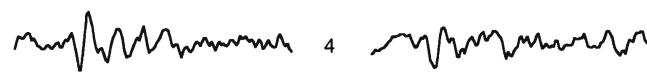

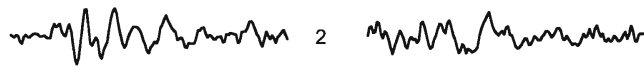

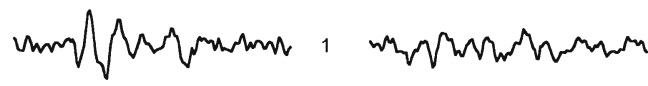
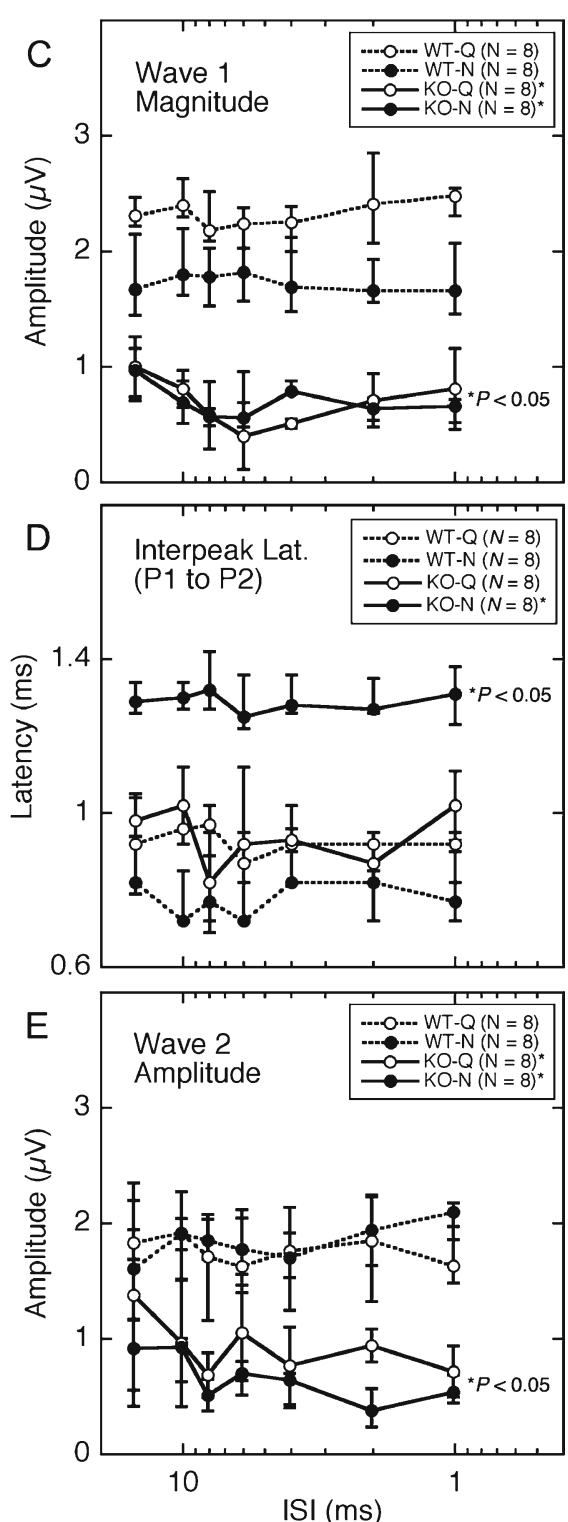

latency (P1 to P2), and wave 2 magnitude. Error bars indicate the inter-quartile range of the distributions. $\alpha 9 \mathrm{KO}$ mice showed statistically smaller wave 1 and 2 magnitudes than quiet-reared WT mice $(P<0.05$, asterisks $)$. Noise-reared $\alpha 9 \mathrm{KO}$ mice also showed longer interpeak latencies.

terminals are rendered non-functional by the genetic deletion of $\alpha 9$ nAChRs.

Because direct histological assessments of the cochlea are not possible during the clinical diagnosis of auditory neuropathy, the condition has been defined by non-invasive physiological measures. The loss of auditory nerve synchrony is indicated by a missing or abnormal ABR. As previously noted (Fig. 8B), noise-reared $\alpha 9 \mathrm{KO}$ mice exhibit disorganized ABR waveforms when the gap interval between stimulus presentations is reduced in time. Cortical potentials show a similar dependence on inter-stimulus intervals in patients with auditory survival patterns (Fig. 9A). The mice also display MOCS innervation, although the cochlear efferent 


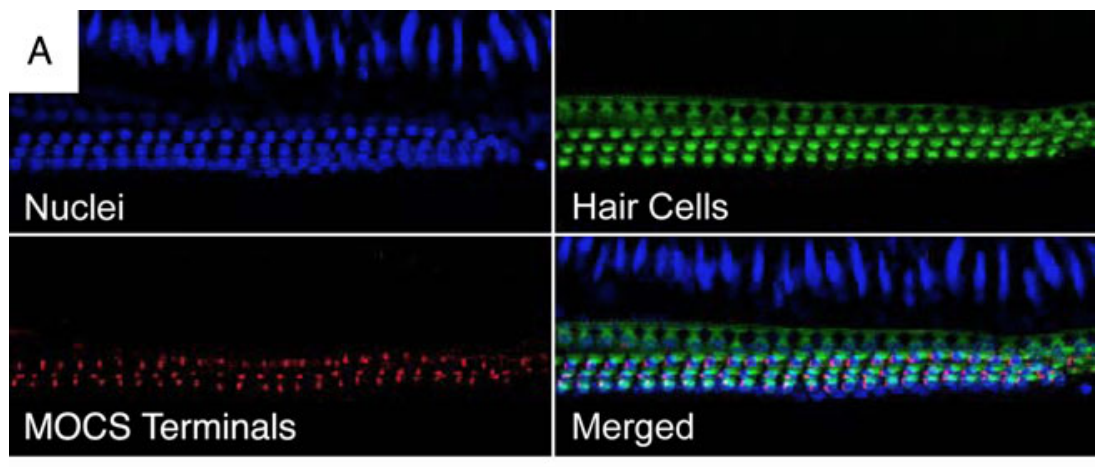

B

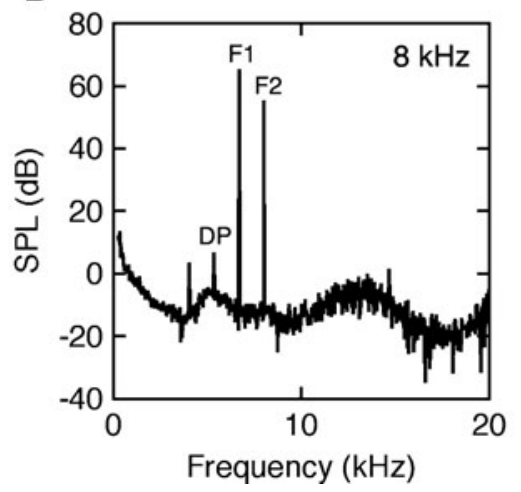

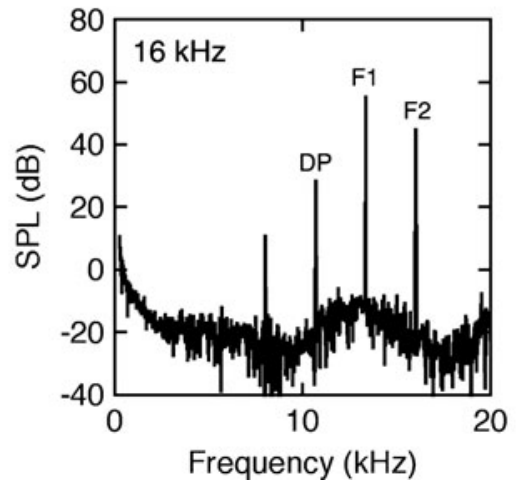

FIG. 9. Normal structure and function of outer hair cells in a noise-reared $\alpha 9 \mathrm{KO}$ mouse. A Middle turn of the cochlea showing a normal complement of outer hair cells and MOCS terminals. Hair cells were immunolabeled with antibodies for DAPI (blue) and myo7a (green). Efferent terminals were immunolabeled with SV2 (red). B Distortion product otoacoustic emissions produced by primary tones (F1 and F2) at frequencies near 8 and $16 \mathrm{kHz}$. A cubic difference distortion product (DP) was generated at both frequencies. neuropathy (Michalewski et al. 2005). The functional integrity of OHCs is established by the presence of DPOAEs or cochlear microphonics. The existence of normal DPOAEs in noise-reared $\alpha 9 \mathrm{KO}$ mice (Fig. 9B) verified an additional clinical marker of the neuropathic condition.

The loss of SGNs is not sufficient to induce the physiological correlates of auditory neuropathy. When inner hair cells and SGNs are damaged with the ototoxic agent carboplatin, ABR measures continue to display synchronized waveforms (El-Badry and McFadden 2009). Because this chemical lesion was made in adult animals, its failure to induce a neuropathic condition suggests that the peripheral insult may be introduced prior to the maturation of auditory nerve inputs to the brainstem.

Statistically significant abnormalities in the magnitude and latency of ABR wave 2 also were observed in $\alpha 9 \mathrm{KO}$ mice. The deficits were magnified by early noise exposures. Later waves of the ABR are produced when discrete populations of central auditory neurons respond with differing latency to the volley of soundevoked activity that is delivered by the auditory nerve. Wave 2 is dominated by the synchronous activity of VCN globular bushy cells (GBCs: Henry 1979; Melcher and Kiang 1996). GBCs receive endbulb synapses from the auditory nerve (Fekete et al. 1984; Rouiller et al. 1986; Redd et al. 2000; Spirou et al. 2005) and respond to sound with short latency and high temporal precision (Joris and Smith 2008).
The effects of acoustic environment on the synaptic development of the VCN have not been described, but the debilitating effects of reduced auditory input are well established (reviewed by Gravel and Ruben 1996; Moore and King 2004; Shepherd et al. 2006). Much of this work has focused on the abnormal ultrastructural features of endbulbs in congenitally deaf animals (Ryugo et al. 1996; Ryugo et al. 1997;

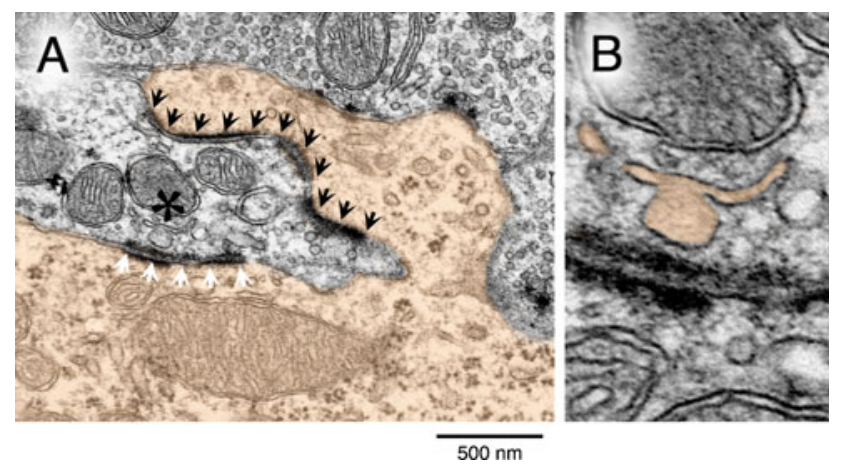

FIG. 10. Abnormal endbulb ultrastructure in a noise-reared $\alpha 9 \mathrm{KO}$ mouse. A The soma of a globular bushy cell (color fill) projects a large somatic spine into a nest of nerve terminals. The endbulb termination of an auditory nerve fiber forms a long, wave-shaped postsynaptic density and puncta adherentia complex with the somatic spine (black arrowheads). A second postsynaptic density and puncta adherentia complex contacts the main somatic surface (white arrowheads). A mitochondrion-adherens complex (MAC) near the somatic synapse displays an abnormal vesicular chain (asterisk). B The vesicular chain of the MAC in higher magnification (color fill). 
Redd et al. 2000; Lee et al. 2003). Subsequent functional assessments have confirmed irregular transmission characteristics (Oleskevich and Walmsley 2002; Oleskevich et al. 2004; Wang and Manis 2005, 2006).

A preliminary ultrastructural analysis of the GBC endbulbs in noise-reared $\alpha 9 \mathrm{KO}$ mice revealed a variety of morphological features that may negatively impact synaptic transmission. Under low magnification, the neuron in Figure 10A was classified as a GBC by its elongated (globular) cell body, eccentric nucleus, and featureless nuclear envelope. Under high magnification, the neuron displayed elaborate axosomatic contacts with the auditory nerve and enlarged postsynaptic densities. Synaptic zones within the endbulb contained few vesicles and there was a conspicuous absence of the intercellular cisternae that is found in normal animals.

The synaptic zones also contained an unusual mitochondrion-associated adherens complex (Tolbert and Morest 1982; Spirou et al. 2005). Because this organelle is uniquely associated with large, temporally secure synapses in the auditory brainstem, it is thought to promote vesicle formation, calcium regulation, and synapse stabilization during the rapid transmission of auditory events (Rowland et al. 2000; Spirou et al. 2005). The vesicular chain in this example is poorly organized and is marked by one aberrantly large vesicle (Fig. 10B). Such irregularities would presumably compromise vesicle recycling and therefore may contribute to unusual ABR responses at rapid rates of stimulation.

\section{Clinical implications}

Hearing impaired listeners often manifest auditory neuropathy as a difficulty understanding speech (Zeng et al. 1999), or in the case of young children, as a delayed acquisition of speech (Berlin et al. 2010). Given the dynamic acoustic properties of speech, it is not surprising that this complex perceptual behavior would be compromised by the type of functional deficits that are evident in the auditory nerve and cochlear nucleus of noise-reared $\alpha 9 \mathrm{KO}$ mice. To simulate the rapid changes in communication sounds, our behavioral paradigm characterized this loss of synchrony in terms of the degraded discrimination of brief silent intervals (gaps). Although clinical descriptions of auditory neuropathy have largely focused on poor speech comprehension, human patients show the same elevation of gap detection thresholds that was demonstrated by $\alpha 9 \mathrm{KO}$ mice (Yalcinkaya et al. 2009).

The increased refinement of newborn screening procedures indicates that auditory neuropathy is unexpectedly prevalent, particularly among young children with hearing loss (Dowley et al. 2009). Commonly cited risk factors include bilirubin toxicity
(Shapiro 2003), low birth weight (Xoinis et al. 2007), and ototoxic exposure (Dowley et al. 2009). Because these medical conditions are often associated with long-term hospitalization in a relatively loud neonatal intensive care unit (NICU) (Benini et al. 1996), many of these children have experienced the type of early noise exposure that was an important environmental risk factor in $\alpha 9 \mathrm{KO}$ mice. The incidence of auditory neuropathy increases dramatically when neonatal screening procedures are limited to individuals who have experienced extended NICU treatment (Berg et al. 2005).

An important function of the MOCS may be to regulate the sound-evoked activity that is essential for the postnatal development of synaptic processing in the auditory nerve and cochlear nucleus. Without this mechanism for controlling cochlear sensitivity, the developing auditory system of $\alpha 9 \mathrm{KO}$ mice is vulnerable to environmental noise levels that are relatively harmless to WT mice. When the strength of MOCS feedback is estimated by measuring the contralateral suppression of transient evoked otoacoustic emissions, children with auditory neuropathy display weak or non-existent suppression effects. These observations support the basic findings of our current experimental approach. The induction of auditory neuropathy is strongly influenced by age, environment, and individual susceptibility.

\section{ACKNOWLEDGMENTS}

This work was supported by NIH grants DC009353, DC000023, and DC005211. We thank Stephanie Saylor and Anna Chambers for assistance with data collection. We also thank Hakim Hiel, Paul Fuchs, Katanyu Pongstaporn, and David Ryugo for valuable discussions and assistance.

\section{REFERENCES}

Benini F, Magnavita V, Lago P, Arslan E, Pisan P (1996) Evaluation of noise in the neonatal intensive care unit. Am J Perinatol 13:37-41

Berg AL, Spitzer JB, Towers HM, Bartosiewicz C, Diamond BE (2005) Newborn hearing screening in the NICU: profile of failed auditory brainstem response/passed otoacoustic emission. Pediatrics 116:933-938

Berlin Ci, Hood LJ, Morlet T, Wilensky D, Li L, Mattingly KR, Taylor-Jeanfreau J, Keats BJ, John PS, Montgomery E, Shallop JK, Russell BA, Frisch SA (2010) Multi-site diagnosis and management of 260 patients with auditory neuropathy/dyssynchrony (auditory neuropathy spectrum disorder). Int J Audiol 49:30-43

Chang EF, Merzenich MM (2003) Environmental noise retards auditory cortical development. Science 300:498-502

Christopher Kirk E, SMITH DW (2003) Protection from acoustic trauma is not a primary function of the medial olivocochlear efferent system. J Assoc Res Otolaryngol 4:445-465 
Dewson JH 3RD, EfFerent OB (1968) Some relationships to stimulus discrimination in noise. J Neurophysiol 31:122-130

Dowley AC, Whitehouse WP, Mason SM, Cope Y, Grant J, GibBin KP (2009) Auditory neuropathy: unexpectedly common in a screened newborn population. Dev Med Child Neurol 51:642-646

EL-BADRY MM, MCFADDEN SL (2009) Evaluation of inner hair cell and nerve fiber loss as sufficient pathologies underlying auditory neuropathy. Hear Res 255:84-90

Fekete DM, Rouiller EM, Liberman MC, Rrugo DK (1984) The central projections of intracellularly labeled auditory nerve fibers in cats. J Comp Neurol 229:432-450

Giraud Al, Garnier S, Micheyl C, Lina G, Chays A, Cherz-Croze S (1997) Auditory efferents involved in speech-in-noise intelligibility. NeuroReport 8:1779-1783

Gravel JS, Ruben RJ (1996) Auditory deprivation and its consequences: From animal models to humans. In: Van De Water T, Popper AN, Fay RR (eds) Clinical Aspects of Hearing. New York, Springer, pp 86-115

HENRY KR (1979) Auditory brainstem volume-conducted responses: origins in the laboratory mouse. J Am Aud Soc 4:173-178

Hoffman HS, Fleshler M (1963) Startle Reaction: Modification by Background Acoustic Stimulation. Science 141:928-930

Ison JR, AlLEN P (2003) A diminished rate of "physiological decay" at noise offset contributes to age-related changes in temporal acuity in the CBA mouse model of presbycusis. J Acoust Soc Am 114:522-528

Ison JR, Agrawal P, Pak J, Vaughn WJ (1998) Changes in temporal acuity with age and with hearing impairment in the mouse: a study of the acoustic startle reflex and its inhibition by brief decrements in noise level. J Acoust Soc Am 104:1696-1704

Ison JR, Allen PD, O’Neill WE (2007) Age-related hearing loss in C57BL/6J mice has both frequency-specific and nonfrequency-specific components that produce a hyperacusislike exaggeration of the acoustic startle reflex. J Assoc Res Otolaryngol 8:539-550

Joris PX, SмITH PH (2008) The volley theory and the spherical cell puzzle. Neurosci 154:65-76

Krizman JL, Skoe E, Kraus N (2010) Stimulus rate and subcortical auditory processing of speech. Audiol Neurootol 15:332-342

KujaWA SG, Liberman MC (2006) Acceleration of age-related hearing loss by early noise exposure: evidence of a misspent youth. J Neurosci 26:2115-2123

Kujawa SG, Liberman MC (2009) Adding insult to injury: cochlear nerve degeneration after "temporary" noise-induced hearing loss. J Neurosci 29:14077-14085

Lauer AM, May BJ, Hao ZJ, Watson J (2009) Analysis of environmental sound levels in modern rodent housing rooms. Lab Anim (NY) 38:154-160

Lee DJ, Cahill HB, Ryugo DK (2003) Effects of congenital deafness in the cochlear nuclei of Shaker-2 mice: an ultrastructural analysis of synapse morphology in the endbulbs of Held. J Neurocytol 32:229-243

Liberman MC (1991) The olivocochlear efferent bundle and susceptibility of the inner ear to acoustic injury. J Neurophysiol 65:123-132

Liberman MC, Brown MC (1986) Physiology and anatomy of single olivocochlear neurons in the cat. Hear Res 24:17-36

Maison S, Micheyl C, Chays A, Collet L (1997) Medial olivocochlear system stabilizes active cochlear micromechanical properties in humans. Hear Res 113:89-98

Maison S, Durrant J, Gallineau C, Micheyl C, Collet L (2001) Delay and temporal integration in medial olivocochlear bundle activation in humans. Ear Hear 22:65-74

MAY BJ, McQuone SJ (1995) Effects of bilateral olivocochlear lesions on pure-tone intensity discrimination in cats. Aud Neurosci $1: 385-400$
May BJ, Budelis J, Niparko JK (2004) Behavioral studies of the olivocochlear efferent system: learning to listen in noise. Arch Otolaryngol Head Neck Surg 130:660-664

Melcher JR, KiAng NY (1996) Generators of the brainstem auditory evoked potential in cat. III: Identified cell populations. Hear Res 93:52-71

Michalewsi HJ, Starr A, Nguyen TT, Kong YY, Zeng FG (2005) Auditory temporal processes in normal-hearing individuals and in patients with auditory neuropathy. Clin Neurophysiol 116:669-680

Moore DR, King AJ (2004) Plasticity of binaural systems. In: Parks TN, Rubel EW, Fay RR, Popper AN (eds) Plasticity of the Auditory System. New York, Springer, pp 96-172

MoOre DR, SHAnNon RV (2009) Beyond cochlear implants: awakening the deafened brain. Nat Neurosci 12:686-691

Oleskevich S, Walmsley B (2002) Synaptic transmission in the auditory brainstem of normal and congenitally deaf mice. J Physiol 540:447-455

Oleskevich S, Youssoufian M, Walmsley B (2004) Presynaptic plasticity at two giant auditory synapses in normal and deaf mice. J Physiol 560:709-719

Rajan R. (1988) Effect of electrical stimulation of the crossed olivocochlear bundle on temporary threshold shifts in auditory sensitivity. I. Dependence on electrical stimulation parameters. J. Neurophysiol., 60:549-568

Redd EE, Pongstaporn T, Ryugo DK (2000) The effects of congenital deafness on auditory nerve synapses and globular bushy cells in cats. Hear Res 147:160-174

Rouiller EM, Cronin-Schreiber R, Fekete DM, Ryugo DK (1986) The central projections of intracellularly labeled auditory nerve fibers in cats: an analysis of terminal morphology. J Comp Neurol 249:261-278

Rowland KC, Irby NK, Spirou GA (2000) Specialized synapseassociated structures within the calyx of Held. J Neurosci 20:9135-9144

Ryugo DK, Wu MM, Pongstaporn T (1996) Activity-related features of synapse morphology: a study of endbulbs of held. J Comp Neurol 365:141-158

Ryugo DK, Pongstaporn T, Huchton DM, Niparko JK (1997) Ultrastructural analysis of primary endings in deaf white cats: morphologic alterations in endbulbs of Held. J Comp Neurol 385:230-244

Ryugo DK, Kretzmer EA, Niparko JK (2005) Restoration of auditory nerve synapses in cats by cochlear implants. Science 310:14901492

Sanes DH, BaO S (2009) Tuning up the developing auditory CNS. Curr Opin Neurobiol 19:188-199

Sanes DH, Constantine-Paton M (1985A) The development of stimulus following in the cochlear nerve and inferior colliculus of the mouse. Brain Res 354:255-267

Sanes DH, Constantine-Paton M (1985B) The sharpening of frequency tuning curves requires patterned activity during development in the mouse, Mus musculus. J Neurosci 5:1152-1166

SANEs DH, WALSh EJ (1998) The development of central auditory processing. In: Rubel EW, Popper AN, Fay RR (eds) Development of the Auditory System. New York, Springer, pp 271-314

ShaprRo SM (2003) Bilirubin toxicity in the developing nervous system. Pediatr Neurol 29:410-421

Shepherd RK, Meltzer NE, Fallon JB, Ryugo DK (2006) Consequences of deafness and electrical stimulation on the peripheral and central auditory system. In: Waltzman SB, Roland JT (eds) Cochlear Implants. Thieme, New York, pp 25-39

Sininger YS, Doyle KJ, Moore JK (1999) The case for early identification of hearing loss in children. Auditory system development, experimental auditory deprivation, and development of speech perception and hearing. Pediatr Clin N Am $46: 1-14$ 
Spirou GA, Rager J, Manis PB (2005) Convergence of auditory-nerve fiber projections onto globular bushy cells. Neurosci 136:843-863

Tallal P, Merzenich M, Miller S, Jenkins W (1998) Language learning impairment: integrating research and remediation. Scand J Psychol 39:197-199

Tolbert LP, Morest DK (1982) The neuronal architecture of the anteroventral cochlear nucleus of the cat in the region of the cochlear nerve root: electron microscopy. Neurosci 7:3053-3067

Vetter De, Liberman MC, Mann J, Barhanin J, Boulter J, Brown MC, Saffiote-Kolman J, Heinemann SF, Elgoyhen AB (1999) Role of alpha9 nicotinic ACh receptor subunits in the development and function of cochlear efferent innervation. Neuron 23:93-103

Wagner W, Frey K, Heppelmann G, Plontke SK, Zenner HP (2008) Speechin-noise intelligibility does not correlate with efferent olivocochlear reflex in humans with normal hearing. Acta Otolaryngol 128:53-60

Walsh EJ, McGee J, McFadden SL, Liberman MC (1998) Long-term effects of sectioning the olivocochlear bundle in neonatal cats. J Neurosci 18:3859-3869

WANG Y, Manis PB (2005) Synaptic transmission at the cochlear nucleus endbulb synapse during age-related hearing loss in mice. J Neurophysiol 94:1814-1824

Wang Y, Manis PB (2006) Temporal coding by cochlear nucleus bushy cells in DBA/2 J mice with early onset hearing loss. J Assoc Res Otolaryngol 7:412-424

WARR WB (1992) Organization of olivocochlear efferent systems in mammals. In: Webster DB, Popper AN, Fay RR (eds) The
Mammalian Auditory Pathway: Neuroanatomy. New York, Springer, pp 410-448

WARR WB, GUINAN JJ JR (1979) Efferent innervation of the organ of corti: two separate systems. Brain Res 173:152-155

WiedERHOLD ML (1970) Variations in the effects of electric stimulation of the crossed olivocochlear bundle on cat single auditory-nerve-fiber responses to tone bursts. J Acoust Soc Am 48:966-977

WinsLOW RL, SACHS MB (1987) Effect of electrical stimulation of the crossed olivocochlear bundle on auditory nerve response to tones in noise. J Neurophysiol 57:1002-1021

Xoinis K, Weirather Y, Mavoori H, Shaha SH, Iwamoto LM (2007) Extremely low birth weight infants are at high risk for auditory neuropathy. J Perinatol 27:718-723

Yalcinkaya F, Muluk NB, Atas A, Keith RW (2009) Random Gap Detection Test and Random Gap Detection Test-Expanded results in children with auditory neuropathy. Int J Pediatr Otorhinolaryngol 73:1558-1563

Zeng FG, Oba S, Garde S, Sininger Y, Starr A (1999) Temporal and speech processing deficits in auditory neuropathy. NeuroReport 10:3429-3435

Zhou X, Merzenich MM (2008) Enduring effects of early structured noise exposure on temporal modulation in the primary auditory cortex. Proc Natl Acad Sci USA 105:4423-4428

Zhou X, Merzenich MM (2009) Developmentally degraded cortical temporal processing restored by training. Nat Neurosci 12:26-28 